\title{
DIVERSIDADE, ETNICIDADE E EDUCAÇÃO BÁSICA: DIÁLOGOS CONTEMPORÂNEOS
}

\author{
DIVERSITY, ETHNICITY AND BASIC EDUCATION: \\ CONTEMPORARY DIALOGUES
}

Jucenilton Alves dos Santos ${ }^{1}$

\begin{abstract}
RESUMO
Este ensaio objetiva discutir alguns aspectos teóricos sobre gênero, etnias, sexualidades, e suas relações com o ambiente escolar presentes em pesquisas de educação no Brasil, correlacionando-as com os principais temas e questões discutidas, assim como as diretrizes que apontam para o enfrentamento dos problemas destacados. É preciso que mostremos à sociedade brasileira os trabalhos que desenvolvemos e realizamos, assim como é necessário questionarmos a importância desse trabalho, pois a produção de conhecimentos científicos devem corresponder às demandas da sociedade na qual estamos inseridos, sociedade essa que se encontra estruturada de maneira desigual e atravessa inúmeras formas de preconceito sendo os relacionados a gênero, sexualidade e etnia alguns exemplos, no âmbito escolar e no cenário nacional como um todo.
\end{abstract}

Palavras-chaves: Educação. Gênero. Sexualidade. Etnia.

\begin{abstract}
This essay aims to discuss some theoretical aspects about gender, ethnicity, sexuality, and their relationship with the school environment present in educational research in Brazil, correlating them with the main themes and issues discussed, as well as the guidelines that point to the confrontation of the problems. It is necessary that we show Brazilian society the works we have developed and carried out, as well as the question of the importance of this work, since the production of scientific knowledge must correspond to the demands of the society in which we are inserted, a society that is structured in an unequal way and crosses innumerable forms of prejudice, being those related to gender, sexuality and ethnicity some examples, in the school context and in the national scene as a whole.
\end{abstract}

Keywords: Education. Gender. Sexuality. Ethnicity

\footnotetext{
${ }^{1}$ Mestre em Letras pela Universidade Estadual do Sudoeste da Bahia - UESB (2015-2017); Especialista em Gestão Escolar - Educação a Distância pela Universidade Federal da Bahia - UFBA (2012-2013); Especialista em Leitura, Produção e Interpretação de Textos pelas Faculdades Integradas Euclides Fernandes - FIEF (20112012); Especialista em Gestão Educacional pela Faculdade de Educação Superior do Piemonte da Chapada FESPC (2011-2012); Graduado em Letras (Língua Portuguesa e Literaturas da Língua Portuguesa) pela Universidade Estadual do Sudoeste da Bahia - UESB (2005-2009). Atualmente é Coordenador TécnicoPedagógico na Secretaria Municipal de Educação e Cultura de Itiruçu-BA.
} 


\section{Revista \\ Debates Insubmissos}

Este ensaio é um dos resultados de uma pesquisa que se dá mediante provocações que há muito tempo povoam minha mente, a exemplo de: meninos e meninas possuem o mesmo interesse pelos estudos?; gênero, sexualidade e etnia são respeitadas e valorizadas no espaço escolar, não devendo ser utilizadas como critério de exclusão social e política?; por que o respeito e a valorização da diversidade sexual não é de fato efetiva?; dentre outras questões.

Mediante constatação in loco com a temática curricular relacionada, a inquietação com o tema se estende e a presente pesquisa torna-se pertinente porque visualiza a crescente preocupação com questões relacionadas à gênero e sexualidade em escolas públicas, assim como a reflexão sobre a prática docente dos profissionais que convivem com o público alvo compreendido por meninos e meninas, pré-adolescentes e também adolescentes de variadas condições sociais. Deste modo, busca-se oferecer suportes instrumentais para uma melhor apropriação da relação existente entre teoria e prática, culminando num fazer pedagógico aprimorado que possibilite conhecimento à docentes de escolas públicas que trabalham com um público cujo gênero, etnia e sexualidade apresentam diferenças.

Trabalhar em conjunto a problemática de gênero, da diversidade sexual e de etnia, que dá margem ao estudo da homofobia e do racismo, não é apenas uma proposta totalmente ousada, mas oportuna e de extrema necessidade principalmente quando se intui relacioná-la à educação. Em nosso país, o estudo destes temas e dos correlativos processos de discriminação social deu origem a campos disciplinares distintos, à diferentes arenas de atuação de ativistas em que o diálogo entre si nem sempre é fácil e, também, às políticas públicas específicas.

Buscamos desenvolver uma postura crítica em relação aos processos de naturalização da diferença, embora reconheçamos que desigualdades sociais e políticas acabam sendo inscritas nos corpos: corpos de homens e mulheres, por exemplo, tornam-se diferentes por meio dos processos de socialização. Isto é observado no âmbito escolar.

A escola é influenciada pelos modos de pensar e de se relacionar da sociedade, ao mesmo tempo em que influencia, contribuindo para suas transformações. Temos na escola as possibilidades de particular contribuição da alteração do processo de discriminações e 


\section{Revista
Debates Insubmissos}

preconceitos. Ela, por seus propósitos e por abrigar diversidades como de origem, gênero, étnico, racial, cultural, dentre outras, torna-se diretamente responsável juntamente com estudantes, família e sociedade em geral por construir caminhos para a eliminação de preconceitos e de práticas de discriminação. Educar para a valorização da diversidade em geral é responsabilidade de toda a sociedade e do Estado e não somente dos que fazem parte do cotidiano escolar. Políticas socioeducativas e práticas pedagógicas de inclusão voltadas para garantir a permanência, formação de qualidade, igualdade de oportunidade e o reconhecimento das diversas orientações sexuais e identidades de gênero vem contribuindo para a melhoria do contexto educacional e apresentam um potencial transformador que ultrapassa os limites da escola, em favor da consolidação da democracia.

É no ambiente educacional que os estudantes podem construir suas identidades individuais e também de grupos, podem exercitar o direito e o respeito às diferenças.

O Brasil vem conquistando importantes resultados no aumento do acesso e no exercício dos direitos, por parte de seus cidadãos. Entretanto, ainda há grandes desafios a vencer, tanto do ponto de vista objetivo, quando se trata da ampliação do acesso à educação básica e de nível médio, assim como do ponto de vista subjetivo, como o respeito e a valorização da diversidade, em vários aspectos.

As discriminações de gênero, étnico-racial e por orientação sexual, como também a violência homofóbica são produzidas em todos os espaços da vida social brasileira, sendo a escola um desses ambientes.

A pesquisa que deu origem a este ensaio procurou: (a) contribuir para a reflexão acerca das relações de gênero, das relações étnico-raciais e da diversidade de orientação sexual no âmbito escolar; (b) ampliar a compreensão sobre a dinâmica dos processos de discriminação na sociedade brasileira, especificamente o racismo e a homofobia, possibilitando o fortalecimento de ações de combate a essas discriminações; (c) colaborar para que a escola não seja um instrumento da reprodução de preconceitos, mas seja espaço de promoção e valorização das 


\section{Revista
Debates Insubmissos}

diversidades que enriquecem a sociedade brasileira; (d) refletir sobre o acesso de todos/as à cidadania e compreender que, dentro dos limites da ética e dos direitos humanos, as diferenças devem ser respeitadas e promovidas e não utilizadas como critérios de exclusão social e política.

No que se refere as questões metodológicas, através da abordagem e levantamento etnográfico que traz contribuições para o campo das pesquisas, optou-se pelo uso da pesquisa qualitativa, pois ela que "responde a questões muito particulares. Ela se preocupa com um nível de realidade que não pode ser quantificado" (MINAYO, 1994, p.21). Permite, assim, melhor configuração do conhecimento sobre o objeto estudado, visto que é centrada no ambiente e suas relações; é descritiva, investigativa e principalmente subjetiva, pois não isenta o pesquisador de suas próprias concepções, porém ele esforça-se para descrever o observado de forma objetiva.

A opção metodológica consiste em realizar pesquisa de campo, pois permite ao pesquisador a descrição e identificação detalhada de como acontece o trabalho daqueles professores que convivem com estudantes de gênero, sexualidade e etnia diversas. $\mathrm{O}$ ambiente da pesquisa é o município de Itiruçu, Bahia, tendo como grupo de amostra um conjunto de docentes e estudantes do Ensino Fundamental e Médio.

Para a coleta de dados, adotamos a observação sistemática, com planejamento, que se realiza em condições que responda aos propósitos preestabelecidos. Ainda foi utilizado o recurso da entrevista semiestruturada, que para Manzini (1990/1991, p.154), este tipo de entrevista está focalizada em um assunto sobre o qual se confecciona um roteiro com perguntas principais, complementadas por outras questões inerentes às circunstâncias momentâneas à entrevista.

Para análise foi definido o método fenomenológico, que se preocupa com a descrição direta da experiência tal como ela é. A realidade é construída socialmente e entendida como o compreendido, o interpretado, o comunicado. Então, a realidade não é única: existem tantas quantas forem as suas interpretações e comunicações. O sujeito/ator é reconhecidamente importante no processo de construção do conhecimento (GIL, 1999, p.42). 


\section{Revista \\ Debates Insubmissos}

\section{III}

As escolas contemporâneas, longe de serem os lugares da homogeneidade cultural, são marcadas pelo encontro e conflito de diferentes grupos. As diferenças são frutos não apenas das desigualdades sociais, já que encontramos mais diferenças do que as divisões entre as classes sociais. A religião pode ser um dos exemplos: uma criança criada por pai e/ou mãe católicos frequentadores de uma Comunidade Eclesial de Base terá uma visão de mundo e um estilo marcado pelo fato de pertencerem a um específico grupo religioso, que obviamente é muito diferente daquele de uma criança, sua vizinha, criada num meio de religião umbanda ou de fiéis da Igreja Universal do Reino de Deus. Essas crianças deverão conviver ainda com aquelas educadas em meios em que a religião não é relevante, ou mesmo em meios visivelmente ateus. É bastante comum encontrarmos nas escolas crianças e adolescentes que exibem com muita alegria para seus professores os símbolos de sua primeira comunhão, enquanto famílias que cultuam religiões de matriz africana são pejorativamente chamadas de "macumbeiras", sendo discriminadas por suas identidades religiosas.

O estereótipo desenvolve-se como uma marca que alimenta os preconceitos ao definir a priori quem são e como são as pessoas nos diferentes espaços em que elas atuam. Dessa maneira, o etnocentrismo se aproxima também do preconceito que se observa nos variados ambientes escolares.

Em nossas escolas, há práticas que sofrem um grande preconceito por parte daqueles que se aproximam do que é considerado "correto" segundo os que detêm o poder. Partindo desta perspectiva, as práticas homossexuais e homoafetivas, são condenadas e consideradas muitas vezes como transtorno, perturbação ou desvio à "normal e natural" heterossexualidade. Aqueles e aquelas que manifestam sentimentos e/ou desejos diferentes dos comportamentos heterossexuais, além de poderem ser condenados por várias religiões podem ser enquadrados/as no campo patológico e estudados/as pela medicina psiquiátrica que buscava a cura para aquele mal. Sendo assim, foi necessária a contribuição de outros setores do conhecimento para acabar com a ideia de "homossexualismo" como doença e inovar os conceitos de homossexualidade e 
de orientação sexual, incluindo a sexualidade como constitutiva da identidade de todas as pessoas, independentemente de sua etnia, raça ou condição social.

De acordo com Scott (1995), a palavra/termo gênero foi proposto por mulheres que buscaram mudar os paradigmas de abordagem científica e não-científica sobre o gênero feminino. Debates acadêmicos nesse âmbito não se centralizam apenas na história das mulheres, mas na compreensão do movimento histórico dos dois gêneros. Não se pautam em um método que aborda apenas a "nova história das mulheres", mas, uma "nova história", na qual as relações de classe, religião, etnia, gênero e sexualidade estão articulados.

Segundo Louro (1997, 2000), é necessário problematizar as representações sociais de gênero e sexualidade, incluindo as que são apresentadas no espaço escolar através de um processo desconstrutivo que supõe o questionamento da identidade dos seres no que se refere à valores e normas. Um procedimento desconstrutivo não elimina o pensamento hierárquico construído historicamente em relação aos gêneros, mas, busca inseri-los nas relações de poder existentes e analisá-los criticamente de maneira a não serem reproduzidas posturas que legitimam as desigualdades de qualquer ordem entre os sujeitos. As identidades são construídas em múltiplas organizações que produzem e reproduzem as diferenças. Entre essas organizações destacam-se a escola, a família, a mídia que, apesar dos movimentos sociais e individuais de resistência, impõem modelos de conduta em acordo com as práticas sociais dominantes e voltadas ao mercado consumidor e produtor.

Neste sentido, de acordo com o que foi refletido aqui e outras considerações, fica claro que a escola é instituição parte da sociedade e por causa disso não deveria se isolar dos benefícios ou das mazelas produzidos por essa mesma sociedade. Ela é, entretanto, influenciada pelas maneiras de pensar e de se relacionar da sociedade, ao mesmo tempo em que os influencia, colaborando para suas transformações. Ao visualizarmos o cenário de discriminações e preconceitos, vemos no espaço escolar as variadas possibilidades de particular contribuição para alteração desse processo. A escola, pela obrigatoriedade legal e por compreender diferentes diversidades (de origem, gênero, sexual, étnico-racial, etc.), torna-se responsável - junto com estudantes, família, comunidade, organizações governamentais e ONG's - por construir caminhos para a diminuição e/ou eliminação de preconceitos e de 
práticas de discriminação. Educar para a valorização da diversidade não é, entretanto, dever apenas daqueles que fazem parte do dia-a-dia escolar; é responsabilidade de toda a sociedade e do Estado.

\section{IV}

No século XX e começo do século XXI as lutas pela igualdade de gênero sobre questões de sexualidade e etnia têm sido constantes. Porém, a permanência de atitudes e convenções sociais discriminatórias, em todas as sociedades, ainda é uma realidade tão persistente quanto naturalizada. O Brasil tem alcançado bons resultados no aumento do acesso e no exercício dos direitos, por parte dos seus respectivos cidadãos. Entretanto, há ainda grandes desafios a serem vencidos, quer do ponto de vista objetivo, a exemplo do aumento do acesso à educação básica e de nível médio e também do ponto de vista subjetivo, a exemplo do respeito e da valorização da diversidade. As distinções de gênero, sexualidade e etnia, assim como a violência causada pela homofobia são produzidas em todos os espaços da vida social brasileira, e reproduzidas também. O ambiente escolar é um desses lugares, o que deveria ser o contrário. Não precisaremos de leis, se não tivermos a mudança de mentalidades e práticas, e em decorrência surge o papel estrutural que adquirem as ações que possibilitam a discussão desses temas, de maneira que motivem a retratação individual e coletiva e possam contribuir para a superação ou supressão de qualquer forma de tratamento preconceituoso.

As concepções de gênero, sexualidade e etnia ao serem levados para a sala de aula em uma perspectiva da valorização da identidade dos múltiplos sujeitos que convivem no mesmo ambiente da escola devem ter uma posição política, com o intuito de desfazer as generalizações que foram atribuídas historicamente a alguns grupos da sociedade. $O$ conceito de gênero a ser trabalhado na escola, deve começar pelo entendimento de como essa concepção de gênero ganhou contornos políticos, conceito que surgiu entre as estudiosas feministas para se confrontar à ideia da essência, afastando qualquer explicação baseada no determinismo biológico, que permitissem explicitar comportamento/atitudes de homens e mulheres, empreendendo assim uma visão naturalista e universal do comportamento. Esse determinismo 


\section{Revista
Debates Insubmissos}

serviu para explicar as desigualdades entre homens e mulheres, através de suas diferenças físicas.

Segundo Louro (1997) e Braga (2007), o vocábulo gênero começou a ser usado para marcar as dessemelhanças existentes entre homens e mulheres que não são apenas de âmbito físico e biológico. Como não há natureza humana da cultura, a diferença sexual anatômica não pode mais ser pensada de forma isolada em relação as construções socioculturais em que estão inseridas. A distinção biológica é o ponto de partida para a configuração social do que é ser homem ou ser mulher na contemporaneidade. O sexo é relacionado ao biológico enquanto o gênero passa a ser uma construção sócio histórica. $O$ conceito de gênero volta-se para dimensão das relações sociais do feminino e do masculino (BRAGA, 2007). Hoje, o conceito de raça quando relacionado à humanidade provoca muitas polêmicas, visto que a área biológica provou que as diferenças genéticas entre os indivíduos são mínimas, por isso não se acredita que seja passível que a humanidade seja constituída por raças.

V.

Neste ensaio foi possível debater acerca das questões de gênero, sexualidade e etnicidade que se apresentam no ambiente escolar, buscando uma sensibilização sobre a importância dessa reflexão para a construção de uma educação que seja efetivamente democrática e igualitária, focalizando a diminuição das desigualdades e/ou diferenças sociais e suscitar questionamentos e inquietações que leve os sujeitos à reflexão sobre as representações de gênero, sexualidade, etnia e suas correlações na educação.

É praticamente comum designar com a expressão gênero as diferenças identificadas entre homens e mulheres, não só no que se refere aos aspectos biológicos, mas, também, aos sociais que estão enredados nessa diferenciação, a exemplo dos aspectos sobre as condições de vida, femininas e masculinas, representadas durante a história da sociedade. A expressão sexualidade, no que lhe diz respeito, é utilizada para se referir às variadas maneiras dos sujeitos viverem seus desejos sexuais: hetero/bi/homossexuais entre outros. 
Consideramos que no âmbito escolar, a sexualidade está presente de maneiras variadas: nos pressupostos a respeito da configuração das famílias, do papel e da conduta de homens e mulheres; nos textos instrucionais e nas práticas pedagógicas; em frases, rabiscos e pichações nos sanitários e nas carteiras/bancas das salas; em olhares provocantes que procuram decotes, pernas, bundas, braguilha; em bilhetinhos apaixonados e recados carregados de malícias; no ato de brincar, nas anedotas e apelidos que condenam/classificam/criticam os meninos mais "delicados" e as moças mais "atiradas", dentre outros. Por isto é tão importante trabalhar pedagogicamente o universo da diversidade dentro e fora da escola.

\section{REFERÊNCIAS}

BRAGA, Eliane Maio. A questão do Gênero e da sexualidade na educação. In: RODRIGUES, Eliane; ROSIN, Sheila Maria (orgs). Infância e práticas educativas. Maringá - Pr. EDUEM. 2007.

FREIRE, Paulo. Pedagogia da autonomia: saberes necessários à prática educativa. São Paulo: Paz e Terra, 1996.

Gênero e diversidade na escola: formação de professoras/es em Gênero, orientação Sexual e

Relações Étnico-Raciais. Livro de conteúdo. Versão 2009. - Rio de Janeiro: CEPESC; Brasília: SPM, 2009.

GIL, Antônio Carlos. Métodos e técnicas de pesquisa social. São Paulo: Atlas, 1999.

LOURO, Guacira Lopes. Corpo, escola e identidade. In: Educação e Realidade, Jul/dez. 2000.

, Guacira Lopes. Gênero, Sexualidade e Educação: Uma perspectiva pós estruturalista.

Petrópolis, Rio de Janeiro: Vozes, 1997.

MANZINI, E. J. A entrevista na pesquisa social. Didática, São Paulo, v. 26/27, p. 149-158, $1990 / 1991$.

MINAYO, M. C. de S. Pesquisa Social: Teoria, método e criatividade. Petrópolis: Vozes, $6^{\text {a }}$ edição, 1994.

SCOTT, Joan. Gênero: uma categoria útil de análise histórica. Educação e Realidade. Vol. 20(2), 1995.

Submetido em: 10/05/2018

Aprovado em: 23/10/2018 